\title{
Lumbar-Sacral Plexus Block Anesthesia versus General Anesthesia for Total Hip Arthroplasty: Case Control Study
}

\author{
Perales Caldera Eduardo ${ }^{*}$ (i), González Lumbreras Aniza Surinam¹, \\ Uribe Campo Giselle Andrea1, Fernández Soto José Rodrigo', Medina de la Rosa Edoardo, \\ Díaz Borjón Efraín², Bravo Reyna Carlos César³ \\ ${ }^{1}$ Department of Anesthesiology, Hospital Ángeles Lomas, México City, Mexico \\ ${ }^{2}$ Department of Orthopaedics, Hospital Ángeles Lomas, México City, Mexico \\ ${ }^{3}$ Department of Experimental Surgery, Instituto Nacional de Ciencias Médicas y Nutrición Salvador Zubirán, México City, Mexico \\ Email: *eperalesc@yahoo.com.mx
}

How to cite this paper: Eduardo, P.C., Surinam, G.L.A., Andrea, U.C.G., Rodrigo, F.S.J., de la Rosa Edoardo, M., Efraín, D.B. and César, B.R.C. (2021) Lumbar-Sacral Plexus Block Anesthesia versus General Anesthesia for Total Hip Arthroplasty: Case Control Study. Open Journal of Anesthesiology, 11, 259-268.

https://doi.org/10.4236/ojanes.2021.119025

Received: July 30, 2021

Accepted: August 30, 2021

Published: September 2, 2021

Copyright $\odot 2021$ by author(s) and Scientific Research Publishing Inc. This work is licensed under the Creative Commons Attribution International License (CC BY 4.0).

http://creativecommons.org/licenses/by/4.0/ (c) (i) Open Access

\begin{abstract}
Background: Peripheral block techniques for total hip arthroplasty have been used as an analgesic strategy, only a few studies described it as an anesthetic technique, so the perioperative performance and safety are poorly studied. Methods: 78 total hip arthroplasties were prospectively observed in our hospital. Divided into 2 groups: 1) General anesthesia; and 2) Lumbar sacral plexus block anesthesia. Variables measured in both groups were: demographics, conversion to general anesthesia, total opioid doses, surgical time, blood loss, postoperative pain, use and total dose of vasopressors drugs, transfusion and ICU transfer needs, postoperative ambulation time, and length of hospital stay. $\mathrm{T}$ student and chi-square tests were used upon the case. A significant difference was considered when a value of $p<0.05$ was obtained. Descriptive statistics were performed in frequency, percentages, variance and standard deviation. Results: 3 patients (7.3\%) anesthetized with combined lumbar sacral plexus block were converted to general anesthesia. When comparing peripheral nerve block and general anesthesia, less intraoperative $(\mathrm{p}=0.000)$ and postoperative $(\mathrm{p}=0.002)$ opioid consumption were noted, less postoperative pain in PACU ( $p=0.002)$ and in the first 24 hours $(p=0.005)$, as well as earlier onset of ambulation $(\mathrm{p}=0.008)$ and shorter hospital stay $(\mathrm{p}=0.031)$. Conclusions: In our study, the lumbar and sacral plexus block anesthesia technique provided anesthetic conditions to perform hip joint arthroplasty and it was proved to be advantageous in comparison to general anesthesia.
\end{abstract}

\section{Keywords}

Anesthetic Technique Conversion, Opioids Requirements, 
General Anesthesia, Regional Anesthesia, Lumbar Plexus Block, Sacral Plexus

Block, Lumbar Sacral Plexus Anesthesia, Success Rate

\section{Introduction}

Currently, anesthetic techniques used for total hip arthroplasty are general anesthesia in $71 \%$ of cases, neuraxial anesthesia in $21.4 \%$, or a combination of the above with peripheral nerve blocks in $7.6 \%$ [1].

Anesthesia alters perioperative outcomes [1] [2] [3]. For example, Peripheral Nerve Blocks (PNB), when combined with other anesthetic techniques for major joint surgery, are associated with improved pain control [4], less opioid consumption [5], surgical wound infections, pulmonary complications, use of resources associated with medical treatment (like transfer to the intensive care unit and need for blood transfusion) [6], the incidence of urinary retention [7], recovery time for joint mobility, and hospital stay [8].

However, peripheral nerve block techniques have also been associated with adverse effects such as muscle weakness and the risk of falls in the postoperative period [7]. This statement has been refuted by Liu, who observed that there was no significant difference in muscle weakness during the first postoperative day in patients who received peripheral block compared to those who did not receive it $(p>0.05)$ [5]. Another risk related to the use of peripheral nerve block is nerve injury, which is estimated to occur in $0.04 \%$ [9] [10].

In general, PNBs are used as part of a postoperative analgesic strategy; therefore, studying cases in which they are used for anesthesia in total hip arthroplasty is the next step to follow. For example, in 2000, a study compared hemodynamic effects with either combined lumbar sacral plexus block or spinal anesthesia and found that hypotension was longer-lasting after spinal anesthesia and more profound in patients over 85 years of age [11]; in 2008, a meta-analysis by Touray et al. reported a $27 \%$ rate of conversion to GA of combined lumbar sciatic PB plus sedation in Hip arthroplasties. In their results report "insufficient evidence" to support the use of these combined peripheral blocks as an alternative to GA [12].

In 2015, Petchara and colleagues published a case series study of 70 geriatric high-risk surgical patients with a combined lumbar and sacral plexus plus sedation for hip fracture repair with hemiarthroplasty, dynamic screw and proximal femur nail, reporting zero conversion to general anesthesia [13]. In 2016, Johnston and colleagues published a study comparing mortality between general anesthesia and anesthesia with iliac fascia compartment block (3-in-1 block) plus sedation. They observed higher mortality in patients who received general anesthesia [14]. In 2019, Mei et al. reported the use of selective Thoracic 12, lumbar and sciatic plexus block plus sedation, as anesthesia for hip arthroplasty in two patients [15].

The objective of this study is to quantify the conversion rate from combined lumbar sacral plexus block anesthesia to general anesthesia, analyze and com- 
pare the different outcomes such as opioid consumption, acute postoperative pain, transfusion requirements, transfer to the intensive care unit, time for ambulation and hospital stay between groups for total hip arthroplasty.

\section{Material and Methods}

This research protocol was reviewed and authorized by the Research Ethics Committee in Hospital Angeles Lomas in México (registration number HAL317/2019).

This is a descriptive, longitudinal, observational, prospective, case control study.

We include all adult patients (total of 94) who underwent for total hip arthroplasty in our hospital, since January of 2018 to December of 2019, the study period was based on the patient's hospital admission and discharge dates, and divided in two groups:

1) Group 1-Combination of lumbar and sacral plexus block plus sedation (lumbar sacral PB) 41 patients;

2) Group 2-Balanced general anesthesia (GA) 37 patients.

16 of 94 patients were excluded since they received neuraxial anesthesia.

\subsection{Data Collection}

During the research period, the hospital's surgery schedule was reviewed daily, and a team member was present observing and collecting data in the preoperative, intraoperative, and postoperative periods in both groups.

Collected data for both groups were presented to a team member for its statistical analysis, this member did not participate in data collection or review of medical records at any time.

In preoperative period: demographic variables such as age, sex, ASA (American Society of Anesthesiology) functional status classification, BMI (Body Mass Index), cardiovascular risk with the RCRI scale (Revised Cardiac Risk Index) [16], number of comorbidities and type of disease, anesthesia, surgery, and preoperative diagnosis were collected.

During intraoperative period, the following variables were recorded: type of surgery, conversion of anesthetic technique (peripheral nerve block to general anesthesia), use and dose of intraoperative vasopressors (converted to norepinephrine) [17], need for intraoperative transfusion, dose of intraoperative opioid (oral morphine equivalency) [18].

In postoperative period variables like transfer to ICU, opioid dose in the first three postoperative days (converted to oral morphine) [16], use of postoperative transfusion, Visual Pain Analogue Scale (VAS) in PACU, and at 24, 48, 72, postoperative hours, use and number of analgesic rescues and hospital stay in hours were recorded.

Clinical records were used to complete data that could not be collected prospectively.

\subsection{Block Technique Description}

All lumbar sacral plexus blocks were observed, the technique used can be sum- 
marized as follows:

1) Prior to the block all patients were monitored and sedated with midazolam/ fentanyl and oxygen, and then skin disinfection with clorhexidine was performed.

2) A 3 - $5 \mathrm{MHz}$ ultrasound probe was coated with a sterile surgical drape and covered with a sterile guard.

3) The lumbar plexus was located upon technique described in 2015 by Karmakar et al. [19], correct location its confirmed with a nerve stimulator (settings: current $0.6 \mathrm{~mA}$, frequency $1 \mathrm{~Hz}$, psoas contraction), then 20 to $25 \mathrm{ml}$ of a combination of ropivacaine at $0.37 \%+$ lidocaine/epinephrine $1 \%$ were administered.

4) Afterwards, the sciatic nerve was located at parasacral level, using ultrasound guidance described by Taha et al. in 2011 [20], the motor response is corroborated with a nerve stimulator (settings: current $0.6 \mathrm{~mA}$, frequency $1 \mathrm{~Hz}$, dorsal flexion, and foot eversion) then 20 or $25 \mathrm{mls}$ of a combination of ropivacaine at $0.37 \%$ plus lidocaine with epinephrine at $1 \%$ were administered.

\subsection{Statistical Analysis}

Statistical analysis was used to describe the frequency of conversion from peripheral nerve block to general anesthesia and to contrast how the two anesthetic techniques influence the outcomes studied.

The sample size calculation:

Population size: 46 average total hip artroplasties per year from 2017 to 2019 are performed at our hospital.

With a Heterogeneity of $50 \%$, margin of error of $5 \%$, confidence level $95 \%$, statistical power 0.8 , a sample size of 42 patients was obtained.

The analysis of comparison of means for independent samples $\mathrm{T}$ student for continuous variables was used, the categorical and dichotomous variables were analyzed through the chi-square test. A value of $\mathrm{p}<0.05$ was taken as significant difference; Descriptive statistics of frequency, percentages, variance and standard deviation were also performed for all study variables.

Data analysis was performed using the statistical program IBM SPSS Statistics for PC version 26.

\section{Results}

During 2018 and 2019, 94 patients underwent total hip arthroplasty at our hospital, 16 patients were excluded since they received another type of anesthesia than those studied.

37 (47.4\%) patients received balanced general anesthesia (GA) and 41 (52.6\%) combined lumbar sacral PB plus sedation guided by ultrasound and neurostimulation in all cases. Patients observed in this study were administered a combination of perineural local anesthetic, with a total fractionated dose of ropivacaine 187.5 - $225 \mathrm{mg}$ and 500 - $600 \mathrm{mg}$ of lidocaine with epinephrine; No local anesthetic toxicity were observed in any case.

Demographic data were compared for both groups and are summarized in 
Table 1. There was no significant difference between groups.

A total of 3 patients $(7.3 \%)$ anesthetized with lumbar sacral plexus block were converted to general anesthesia, since they did not have optimal anesthetic conditions for surgery. (Success rate 93.7\%). When comparing the mean dose of opioid used intraoperatively and postoperatively, a lower consumption of opioids was observed in the lumbar sacral PB anesthesia group compared to GA, with a significant $\mathrm{p}$ value for both comparisons (Table 2).

Table 1. Demographics.

\begin{tabular}{|c|c|c|c|c|}
\hline \multicolumn{2}{|l|}{ Variable } & \multirow{2}{*}{$\begin{array}{l}\text { Lumbar sacral PB } \\
\mathbf{n}=(41) 52.6 \% \\
(28-91) 68 \pm 12.3\end{array}$} & \multirow{2}{*}{$\begin{array}{l}\text { General Anesthesia } \\
\text { n }=(37) 47.4 \% \\
(40-92) 70 \pm 14\end{array}$} & \multirow{2}{*}{$\begin{array}{c}\text { p value } \\
\text { NS }\end{array}$} \\
\hline Age (Range) & & & & \\
\hline Genere n (\%) & Female & $31(76)$ & $22(60)$ & NS \\
\hline BMI $^{1}$ (Range) & & (17.3 - 39) $24 \pm 5$ & $(20-40) 26 \pm 5$ & NS \\
\hline Comorbidities n (\%) & Less than 2 & $25(61)$ & $20(54)$ & NS \\
\hline & $>2$ & $5(12.2)$ & $5(13.5)$ & \\
\hline \multirow[t]{2}{*}{$\begin{array}{l}\text { Risk }^{2} \\
\text { n (\%) }\end{array}$} & Class 1 & $34(83)$ & $31(84)$ & NS \\
\hline & Class 2 & $7(17.1)$ & $6(16.2)$ & \\
\hline \multirow[t]{4}{*}{ ASA Physical Status ${ }^{3}$ n (\%) } & I & $9(22)$ & $12(32.4)$ & NS \\
\hline & II & $26(63.4)$ & $21(57)$ & \\
\hline & III & $4(10)$ & $3(8.1)$ & \\
\hline & IV & $2(5)$ & $1(3)$ & \\
\hline \multirow[t]{3}{*}{ Surgical Diagnosis n (\%) } & Hip arthrosis & $27(66)$ & $19(51.4)$ & NS \\
\hline & Hip Fracture & $12(29.3)$ & $17(46)$ & \\
\hline & Other ${ }^{4}$ & $2(5)$ & $1(3)$ & \\
\hline
\end{tabular}

Tstudent analysis, chi square test. Lumbar sacral PB: combined lumbar sacral plexus block; ${ }^{1} \mathrm{BMI}$ : Body Mass Index; ${ }^{2}$ Cardiovascular risk: Revised Cardiac Risk Index 2013; ${ }^{3}$ ASA: American Society of Anesthesiology Physical Status; ${ }^{4}$ Other: (Osteonecrosis, Pseudoarthrosis); NS: No significant.

Table 2. Perioperative mean opioid dose between anesthetic techniques (adjusted dose converted to oral morphine).

\begin{tabular}{cccc}
\hline & General Anesthesia & Lumbar sacral PB \\
$\mathbf{n}=37$ & $\mathbf{n}=38$ & p value \\
Transoperative dose (mg) & $44 \pm 19$ & $18.1 \pm 6^{*}$ & 0.000 \\
Postoperative dose (mg) (3 days mean) & $43.4 \pm 48$ & $14.3 \pm 30^{*}$ & 0.002 \\
\hline
\end{tabular}

T student analysis. 
A difference was founded in favor of GA when comparing vasopressor use, however, when comparing the adjusted mean vasopressor dose, nonsignificant difference was observed between the groups (Table 3).

Regarding the need for blood transfusion and the requirement to transfer to the intensive care unit, no significant difference was observed between the two groups (Table 4).

There were two times when postoperative pain was significantly lower in the lumbar sacral PB anesthesia group compared to GA and these were during the patient's stay in the postoperative care unit and in the first 24 hours (Table 5).

The mean number of analgesic rescues used by patients receiving BNP anesthesia was $0.6 \pm 1.3$ rescues compared to $0.5 \pm 1$ rescues for AGB, with a p-value $=0.806$.

The hospital stay was longer in the GA group than in the lumbar sacral PB anesthesia group ( $4 \pm 2$ days vs $3 \pm 1$ days respectively) $\mathrm{p}=0.031$ (Table 6).

The mean time to start ambulation after surgery in lumbar sacral PB anesthesia was $24 \pm 7.4$ hours (Table 7).

\section{Discussion}

The lumbar sacral PB anesthesia for hip arthroplasty is not universally chosen as

Table 3. Transanesthetic use of vasopressor between techniques (converted to norepinephrine $\mathrm{mcg}$ ).

\begin{tabular}{cccc} 
Variable & $\begin{array}{c}\text { General Anesthesia } \\
\mathbf{n}=37\end{array}$ & $\begin{array}{c}\text { Lumbar sacral PB } \\
\mathbf{n}=38\end{array}$ & p value \\
\hline $\begin{array}{c}\text { Vasopressor use* } \mathbf{n}(\%) \\
\begin{array}{c}\text { Adjusted mean dose of } \\
\text { vasopressor** }(\mathrm{mcg})\end{array}\end{array}$ & $9(24.3)$ & $18(47.4)$ & 0.038 \\
\hline
\end{tabular}

${ }^{\star}$ Chi square test; ${ }^{* *} \mathrm{~T}$ de student analysis; mcg: micrograms; NS: Nonsignificant.

Table 4. Comparison of different variables between groups.

\begin{tabular}{|c|c|c|c|c|}
\hline Variable & & $\begin{array}{l}\text { General Anesthesia } \\
\qquad \mathbf{n}=37\end{array}$ & $\begin{array}{c}\text { Lumbar sacral PB } \\
\qquad \mathrm{n}=38\end{array}$ & p value \\
\hline & & n (\%) & n (\%) & \\
\hline \multirow[t]{2}{*}{$\begin{array}{c}\text { Need for blood } \\
\text { transfusion (trans) }\end{array}$} & Yes & $2(5.4)$ & $0(0)$ & NS \\
\hline & No & $35(94.6)$ & $38(100)$ & NS \\
\hline \multirow[t]{2}{*}{$\begin{array}{c}\text { Need for blood } \\
\text { transfusion (post) }\end{array}$} & Yes & $7(19)$ & $2(5.3)$ & NS \\
\hline & No & $30(80.1)$ & $36(94.7)$ & NS \\
\hline \multirow[t]{2}{*}{ ICU transfer } & Yes & $5(13.5)$ & $2(5.3)$ & NS \\
\hline & No & $32(86.5)$ & $36(94.7)$ & NS \\
\hline
\end{tabular}

Chi square test; Lumbar sacral PB: combined lumbar sacral plexus block anesthesia; ICU: Intensive Care Unit; NS: No significant; trans: Transanesthetic period; post: Postanesthetic period. 
Table 5. Postoperative pain comparison between groups (visual analogue scale evaluation).

\begin{tabular}{cccc}
\hline Postoperative time & $\begin{array}{c}\text { General Anesthesia } \\
\mathbf{n}=\mathbf{3 7}\end{array}$ & $\begin{array}{c}\text { Lumbar sacral PB } \\
\mathbf{n}=\mathbf{3 8}\end{array}$ & p value \\
\hline PACU & $2.1 \pm 3$ & $0.5 \pm 1.5^{*}$ & 0.002 \\
$\mathbf{2 4} \mathbf{h r}$ & $3 \pm 3$ & $1.1 \pm 2.2^{*}$ & 0.005 \\
$\mathbf{2 4}-\mathbf{4 8} \mathrm{hr}$ & $2 \pm 2.3$ & $1.2 \pm 3$ & NS \\
$\mathbf{4 8}-\mathbf{7 2} \mathbf{h r}$ & $1.1 \pm 2.1$ & $1.4 \pm 3$ & NS \\
$>\mathbf{7 2} \mathbf{~ h r}$ & $0.4 \pm 1.1$ & $0.6 \pm 2$ & NS \\
Need for analgesic Rescue: Yes & $10(27)$ & $10(26.3)$ & NS \\
No & $27(73)$ & $28(73.7)$ & NS \\
\hline
\end{tabular}

T student analysis; Lumbar sacral PB: Combined Lumbar sacral plexus block plus sedation; PACU: Postanesthesia care unit; NS: No significant.

Table 6. Hospital stay between groups.

\begin{tabular}{cccc}
\hline & $\begin{array}{c}\text { General Anesthesia } \\
\mathbf{n}=\mathbf{3 7}\end{array}$ & $\begin{array}{c}\text { Lumbar sacral PB } \\
\mathbf{n}=\mathbf{3 8}\end{array}$ & p value \\
\hline (Range) & (Range) & \\
Days & $4 \pm 2(2-12)$ & $3 \pm 1(2-7)$ & 0.031 \\
\hline
\end{tabular}

T student analysis; Lumbar sacral PB: Combined Lumbar sacral plexus block plus sedation.

Table 7. Post-surgery ambulation time between groups in hours.

\begin{tabular}{lccc}
\hline & $\begin{array}{c}\text { General Anesthesia } \\
\mathbf{n}=\mathbf{2 6}\end{array}$ & $\begin{array}{c}\text { Lumbar sacral PB } \\
\mathbf{n}=\mathbf{3 8}\end{array}$ & P value \\
\hline Post surgery hours & $38 \pm 30.4$ & $24 \pm 7.4$ & 0.008 \\
\hline
\end{tabular}

T student analysis; Lumbar sacral PB: Combined lumbar sacral plexus block anesthesia.

intraoperative anesthetic management, however, in our hospital most of the hip joint replacement surgeries are performed under this anesthetic technique.

The purpose of this study was to observe whether adequate anesthesia with lumbar sacral PB plus sedation is possible for total hip arthroplasty. Objectively, this was measured by the need for conversion to general anesthesia, causes of conversion were incomplete blockage and the inability to maintain a patent airway during sedation.

Our observation, the lumbar sacral PB anesthesia conversion to general anesthesia is like the previously reported technique of iliac fascia blockade ( 3 at 1 ) plus sedation ( $7.3 \%$ vs $7.2 \%$ respectively) [12]. In addition, as mentioned by different authors, given it is a blocking technique guided by ultrasound and neurostimulation, it is safer and more effective.

There is an ongoing debate about the risks and benefits of using peripheral regional anesthesia versus other anesthetic techniques [4]-[10]. In this study, the peripheral nerve block technique proved to be associated with significantly less opioid use, better pain control in the PACU and in the first 24 postoperative 
hours, as well as fewer days of hospital stay and onset of ambulation faster than with general anesthesia, we did not observe muscle weakness, falls, or injury nervous in this series of consecutive patients.

However, we also observed a higher requirement for vasopressor in the group of patients undergoing peripheral nerve block, this may be due to different causes such as variability in the diagnostic criteria of intraoperative arterial hypotension and its management or be a reversible consequence of the drugs used in blockade plus sedation; It should be mentioned that transfer to the ICU was not significant between both groups, which supports the premise that there is no serious hemodynamic repercussion in patients with arterial hypotension. Nevertheless, a study in which the hemodynamic stability is the main question is important to revised; in 2015 two studies [12] [21] and found less hemodynamic derangements in patients receiving lumbar sacral PB in comparison to those receiving general anesthesia. Authors hypothesize that this difference could be attributed to lower opioid use among patients receiving peripheral nerve blocks [18].

Regarding the need for intraoperative transfusion, a lower incidence has been shown when general anesthesia is used in combination with peripheral regional block vs general anesthesia [22], however, in our study there was no significant difference between both techniques. Additionally, Buckenmaier et al. [23], reported less bleeding in the peripheral nerve block group vs balanced general anesthesia (224 $\pm 75 \mathrm{ml}$. vs $368 \pm 168 \mathrm{ml}$ ), being statistically significant ( $\mathrm{p}<$ 0.000 ), however this can be attributed to other types of variables such as the experience of the patient surgeon, or the use of antifibrinolytics.

In the use and the number of analgesic rescues received, no statistically significant difference was observed either, but the decreased use of trans and postoperative opioids observed in the group with peripheral nerve block anesthesia is notable $(\mathrm{p}=0.000)$.

Currently the ASRA (American Society of Regional Anesthesia and Pain Medicine) and ESRA (The European Society of Regional Anesthesia and Pain Therapy) emphasize the use of regional anesthesia, since they are non-aerosolgenerating procedures that reduce the risk of transmission of COVID 19 among healthcare personnel [24]. A recent study reported that $33 \%$ of healthcare personnel who developed COVID 19 participated in endotracheal intubation. Likewise, in 2012, a systematic review showed in 7 of 8 studies that health personnel who were exposed to endotracheal intubation of patients with SARS-CoV 2 had a higher risk of transmission than personnel who were not exposed [19].

\section{Conclusion}

The combined lumbar sacral block technique as an anesthetic technique for hip arthroplasty provides optimal conditions for surgery, is safe and does not delay postoperative physiotherapy in total hip arthroplasty patients.

\section{Acknowledgements}

We thank the Department of Anesthesiology at Hospital Angeles Lomas for all 
the facilities to carry out this study.

\section{Conflicts of Interest}

The authors declare no conflicts of interest regarding the publication of this paper.

\section{References}

[1] Elmofty, D.H. and Buvanendran, A. (2017) Regional Anesthesia in Total Joint Arthroplasty: What Is the Evidence? The Journal of Arthroplasty, 32, S74-S76. https://doi.org/10.1016/j.arth.2017.05.017

[2] Shiu, Y.F. and Lawmin, J.C. (2015) Anaesthesia for Joint Replacement Surgery. Anaesthesia and Intensive Care Medicine, 16, 89-92. https://doi.org/10.1016/j.mpaic.2014.12.009

[3] Cozowicz, C., Poeran, J., Zubizarreta, N., Mazumdar, M. and Memtsoudis, S.G. (2016) Trends in the Use of Regional Anesthesia. Regional Anesthesia \& Pain Medicine, 41, 43-49. https://doi.org/10.1097/AAP. 0000000000000342

[4] Hadzic, A., Karaca, P.E., Hobeika, P., Unis, G., Dermksian, J., Yufa, M., et al. (2005) Peripheral Nerve Blocks Result in Superior Recovery Profile Compared with General Anesthesia in Outpatient Knee Arthroscopy. Anesthesia \& Analgesia, 100, 976-981. https://doi.org/10.1213/01.ANE.0000150944.95158.B9

[5] Liu, J., Yuan, W., Wang, X., Royse, C.F., Gong, M., Zhao, Y., et al. (2014) Peripheral Nerve Blocks versus General Anesthesia for Total Knee Replacement in Elderly Patients on the Postoperative Quality of Recovery. Clinical Interventions in Aging, 9, 341-350. https://doi.org/10.2147/CIA.S56116

[6] Memtsoudis, S.G., Poeran, J., Cozowicz, C., Zubizarreta, N., Ozbek, U. and Mazumdar, M. (2016) The Impact of Peripheral Nerve Blocks on Perioperative Outcome in Hip and Knee Arthroplasty-A Population-Based Study. Pain, 157, 2341-2349. https://doi.org/10.1097/j.pain.0000000000000654

[7] Anastase, D.M., Florescu, S.C., Munteanu, A.M., Ursu, T. and Stoica, C.I. (2014) Analgesic Techniques in Hip and Knee Arthroplasty: From the Daily Practice to Evidence-Based Medicine. Anesthesiology Research and Practice, 2014, Article ID: 569319. https://doi.org/10.1155/2014/569319

[8] Liu, Q., Chelly, J.E., Williams, J.P. and Gold, M.S. (2015) Impact of Peripheral Nerve Block with Low Dose Local Anesthetics on Analgesia and Functional Outcomes Following Total Knee Arthroplasty: A Retrospective Study. Pain Medicine, 16, 998-1006. https://doi.org/10.1111/pme.12652

[9] Rensing, N., Fillinger, M.E. and Goodman, G.P. (2018) Rapid Recovery Anesthesia in Total Joint Arthroplasty. Recent Advances in Arthroplasty, 2, 39-41.

[10] Eroglu, A. (2016) Regional Anesthesia Techniques in Orthopedic Surgery. Journal of Anesthesia \& Critical Care: Open Access, 5, Article ID: 00182. https://doi.org/10.15406/jaccoa.2016.05.00182

[11] de Visme, V., Picart, F., Le Jouan, R., Legrand, A., Savry, C. and Morin, V. (2000) Combined Lumbar and Sacral Plexus Block Compared with Plain Bupivacaine Spinal Anesthesia for Hip Fractures in the Elderly. Regional Anesthesia \& Pain Medicine, 25, 158-162. https://doi.org/10.1097/00115550-200003000-00005

[12] Touray, S.T., de Leeuw, M.A., Zuurmond, W.W.A. and Perez, R.S.G.M. (2008) Psoas Compartment Block for Lower Extremity Surgery: A Meta-Analysis. British Journal 
of Anaesthesia, 101, 750-760. https://doi.org/10.1093/bja/aen298

[13] Petchara, S., Paphon, S., Vanlapa, A., Boontikar, P. and Disya, K. (2015) MD Combined Lumbar-Sacral Plexus Block in High Surgical Risk Geriatric Patients Undergoing Early Hip Fracture Surgery. Malaysian Orthopaedic Journal, 9, 28-34. https://doi.org/10.5704/MOJ.1511.004

[14] Johnston, D.F., Stafford, M., McKinney, M., Deyermond, R. and Dane, K. (2016) Peripheral Nerve Blocks with Sedation Using Propofol and Alfentanil Target-Controlled Infusion for Hip Fracture Surgery: A Review of 6 Years in Use. Journal of Clinical Anesthesia, 29, 33-39. https://doi.org/10.1016/j.jclinane.2015.10.012

[15] Mei, B., Lu, Y., Liu, X., Zhang, Y., Gu, E. and Chen, S. (2019) Ultrasound-Guided Lumbar Selective Nerve Root Block Plus T12 Paravertebral and Sacral Plexus Block for Hip and Knee Arthroplasty: Three Case Reports. Medicine, 98, Article ID: e15887. https://doi.org/10.1097/MD.0000000000015887

[16] Davis, C., Tait, G., Carroll, J., Wijeysundera, D.N. and Beattie, W.S. (2013) The Revised Cardiac Risk Index in the New Millennium: A Single-Centre Prospective Cohort Re-Evaluation of the Original Variables in 9,519 Consecutive Elective Surgical Patients. Canadian Journal of Anesthesia, 60, 855-863.

https://doi.org/10.1007/s12630-013-9988-5

[17] Fellahi, J., Poignant, E. and Jacquet-Lagreze, M. (2018) Les dangers de la phényléphrine. Le Pract Anestésie Réanimation, 22, 320-325.

https://doi.org/10.1016/j.pratan.2018.10.007

[18] Treillet, E., Laurent, S. and Hadjiat, Y. (2018) Practical Management of Opioid Rotation and Equianalgesia. Journal of Pain Research, 11, 2587-2601.

https://doi.org/10.2147/JPR.S170269

[19] Karmakar, M.K., Li, J.W., Kwok, W.H. and Hadzic, A. (2015) Ultrasound-Guided Lumbar Plexus Block Using a Transverse Scan through the Lumbar Intertransverse Space: A Prospective CASE series. Regional Anesthesia \& Pain Medicine, 40, 75-81. https://doi.org/10.1097/AAP.0000000000000168

[20] Taha, A.M. (2012) A Simple and Successful Sonographic Technique to Identify the Sciatic Nerve in the Parasacral Area. Canadian Journal of Anesthesia/Journal canadien d'Anesthésie, 59, 263-267. https://doi.org/10.1007/s12630-011-9630-3

[21] Utebey, G., Akkaya, T., Alptekin, A., Sayin, M., Gumus, H. and Ateş, Y. (2009) The Effects of Lumbar Plexus Block and Epidural Block on Total Blood Loss and Postoperative Analgesia in Total Hip Arthroplasty. The Journal of the Turkish Society of Algology, 21, 62-68.

[22] Kratz, T., Dette, F., Schmitt, J., Wiesmann, T., Wulf, H. and Zoremba, M. (2015) Impact of Regional Femoral Nerve Block during General Anesthesia for Hip Arthroplasty on Blood Pressure, Heart Rate and Pain Control: A Randomized Controlled Study. Technology and Health Care, 23, 313-322.

https://doi.org/10.3233/THC-150898

[23] Buckenmaier, C.C., Xenos, J.S. and Nilsen, S.M. (2002) Lumbar Plexus Block with Perineural Catheter and Sciatic Nerve Block for Total Hip Arthroplasty. The Journal of Arthroplasty, 17, 499-502. https://doi.org/10.1054/arth.2002.32176

[24] Uppal, V., Sondekoppam, R.V., Landau, R., El-Boghdadly, K., Narouze, S. and Kalagara, H.K.P. (2020) Neuroaxial Anesthesia and Peripheral Nerve Blocks during the COVID19 Pandemic: A Literature Review and Practice Recommendations. Anaesthesia, 75, 1350-1363. https://doi.org/10.1111/anae.15105 